\title{
Multiple Mini Interview as a Selection Tool for Initial Teacher Education Admissions
}

Riitta-Leena Metsäpelto ${ }^{1}$, Jukka Utriainen ${ }^{1}$, Anna-Maija Poikkeus ${ }^{1}$, Joona Muotka², Asko Tolvanen $^{3}$ and Anu Warinowski ${ }^{4}$

${ }^{1}$ Department of Teacher Education, University of Jyväskylä, Finland

${ }^{2}$ Department of Psychology, University of Jyväskylä, Finland

${ }^{3}$ Faculty of Education and Psychology, University of Jyväskylä, Finland

${ }^{4}$ Faculty of Education, University of Turku, Finland

This working paper reports in-progress work that is not yet peer reviewed. The purpose of the working paper is to stimulate discussion and to contribute to the advancement of knowledge.

This study has been financed by the Finnish Ministry of Education and Culture and Academy of Finland (Nr. 292466). Correspondence concerning this article should be addressed to: Riitta-Leena Metsäpelto, Department of Teacher Education, P.O. Box 35, 40014 University of Jyväskylä, Finland.

E-mail: riitta-leena.metsapelto@jyu.fi

Phone: +358408053349 


\begin{abstract}
The aim of the present study was to investigate the reliability and utility of the Multiple Mini Interview (MMI) format in initial teacher education selections in Finland. The data was comprised of applicants' scores in a five-station MMI $(n=418)$, their perceptions of the validity of MMI collected using a web-survey $(n=304)$ as well as the interviewers' $(n=28)$ ratings of the utility of the MMI. Intraclass correlations (ICCs) indicated mostly small (under $10 \%)$ effects of clustering of applicants to different interviewers and to five-station circuits, but for two stations, ICCs indicated a slightly stronger interviewer effect. In the crossclassified multilevel modelling, percentages of variance in the MMI total score explained by the interviewer or the circuit were found to be low or minimal, whereas the variance component for the MMI stations was somewhat higher indicating varying levels of difficulty between stations. Associations of MMI scores with applicants' gender or age were minimal. The applicants' and interviewers' perceptions of the MMI were mostly positive. Overall, the study provides evidence for the utility of the MMI as a reliable tool for initial teacher education selections.
\end{abstract}


Multiple Mini Interview in initial teacher education admissions 3

\section{Multiple Mini Interview as a Selection Tool for Initial Teacher Education}

\section{Admissions}

Selection of students into university-based initial teacher education (ITE) programs is often based on the applicant's general academic achievement in their final year of secondary school (Ingvarson, 2013). Yet, in some countries, such as Finland, most ITE programs are highly competitive (with acceptance rates of less than 10\%) and involve a broader researchbased screening of applicants. The student selection phase constitutes a critical foundation for subsequent teaching quality, which as a whole is acknowledged to be tantamount to the success of an educational system (Kelly et al., 2018). High teaching quality emerges from a combination of desired pre-existing competencies (e.g., strong social and academic skills), effective support for competence growth in initial teacher education, and continuing professional development throughout a career (Klassen \& Kim, 2017). Recent years have witnessed an increasing interest in teacher education selection (Bowles et al., 2014; Klassen \& Kim, 2018) and a concerted effort to improve the process by developing more reliable and valid selection methods (Klassen et al., 2020).

In fields such as medicine, a strong research base for student selection has been accumulated aiming at development of effective and reliable methods (Patterson et al., 2016), but this is not the case in the field of education where selection methods have been claimed to be less than optimal (Klassen \& Kim, 2018). Information is scant on the reliability of selection methods in initial teacher education, the extent to which different applicant groups (e.g., females and males or younger and more mature applicants) are treated equally, and on how applicants and interviewers perceive the selection methods. The present study addresses this research gap with respect to one specific student selection approach, the Multiple Mini Interview. 
Multiple Mini Interview in initial teacher education admissions 4

\section{Multiple Mini Interview}

The Multiple Mini Interview (MMI) format represents a relatively recent development in admissions for initial teacher education and was originally designed for assessment of applicants' non-cognitive characteristics in medical education selections (Eva et al., 2004). In the MMI, applicants move through a number of interview stations in which they respond to a set of predefined questions on a topic, dilemma or case-based scenario while being rated by an interviewer using a standard scoring scheme. Thus, MMI follows a multiple independent sampling methodology (Hanson et al., 2012) where an applicant is interviewed successively by several interviewers each of whom assess the applicant independently on a specific topic. This format contrasts with semi-structured panel interviews where interviewers present openended questions that allow a conversation with the interviewee on loosely defined themes. The design of MMI (i.e., the constructs being measured, the number and duration of stations and the scoring system) is adjustable to the specific demands of the institution, which makes it more an assessment approach or format than a standard measurement method (Reiter et al., 2012).

Compared to traditional semi-structured interviews, the MMI format has several advantages. Semi or unstructured interviews are known to suffer from poor psychometric properties (e.g., Salvatori, 2001; Siu \& Reiter, 2009), whereas research on MMIs in medical student selection shows relatively high reliability and low interviewer effects (Knorr \& Hissbach, 2014; Patterson et al., 2016; Pau et al., 2013). There is also evidence for criterionbased validity where MMIs predict academic success in medical education and performance in working life (e.g., medical council examinations, tests of clinical skill performance) (see Knorr \& Hissbach, 2014; Patterson et al., 2016; Pau et al., 2013; Reiter et al., 2007). MMI scores used in combination with cognitive skills measures have been found to predict a lower likelihood for dropping out of education among psychology students (Makransky et al., 
2017), whereas low MMI scores have been shown to predict academic difficulties (e.g., delayed progression, low course grades) among pharmacy students (Heldenbrand et al., 2016). A strength of the approach is that MMI performance does not appear to benefit from coaching (Griffin et al., 2008) or suffer from violations of MMI test security (Reiter et al., 2006).

In sum, the MMI format has consistently been proven to be among the strongest selection methods and most frequently studied approaches in medical education (e.g., Patterson et al., 2016). Its favourable psychometric properties provide a strong impetus to apply it in the field of education. The present study is among the first to investigate the reliability and utility of MMI in student selections in teacher education.

\section{Reducing Interviewer Bias in MMI}

Traditional selection interviews have been criticised for being susceptible to biases that stem, for instance, from interviewers' occupational stereotypes and expectations, the unstructured interview situation and flawed judgment based on inferences from limited or biased information (Ebmeir \& Ng, 2005). Consequently, an applicant's success in the selection interview may at least partly be a product of the interviewer's characteristics, leading to poorly justified selection decisions. It has been shown, for instance, that almost a $56 \%$ share of the variance of scores from traditional interviews for the average and lowachieving applicants were attributed to interviewer variability (Harasym et al., 1996).

An effective means to reduce interviewer bias and to increase reliability is using a highly structured interview format (e.g., Ebmeier \& Ng, 2005) like the Multiple Mini Interview, which is based on predefined constructs being assessed, standard, uniformly applied questions across interviewers to target the constructs and systematic scoring rubrics that are employed consistently across all stations and applicants by the carefully trained interviewers. The meticulous structuring seeks to reduce and minimize differences between 
Multiple Mini Interview in initial teacher education admissions 6

interviewers regarding how they conduct the interview and apply the scoring rubric. Without these precautions in a situation where an interviewer has a large number of applicants to assess, the risk is that the assessments by the interviewer will begin to resemble each other and lead to problems of reliability. A critical precondition to MMI reliability is that variance due to the interviewer, the interview station or the circuit of stations (among multiple parallel circuits) is minimal (Knorr \& Hissbach, 2014) and that applicant characteristics explain the majority of variance in MMI scores. Prior research in medical education selections has provided evidence of the success of MMI in reducing construct-irrelevant and therefore 'unwanted' variance (Roberts et al., 2010). In some studies, the variance of the MMI score accounted by the interviewer has varied from $14 \%$ to $21 \%$, and the proportion of individual stations from $2 \%$ to $5 \%$ (Eva et al., 2004b; Roberts et al., 2010). To the best of our knowledge, no prior research has examined the reliability of MMI in teacher education selection. The first goal of the present study was to investigate the extent of interviewer bias using two approaches: focusing on the effect of clustering of applicants to different interviewers and circuits and on the degree of 'unwanted' variance in MMI scores, that is, variance explained by different interviewers, stations and circuits of stations.

\section{Adverse Impact of Gender and Age}

Fair treatment of applicants in the selection process is important to ensure equal opportunities to access initial teacher education. For instance, the distribution of female and male students in teacher education programs has been a much-discussed topic (Sabbe $\&$ Aelterman, 2007). An increase in the proportion of male teachers in primary schools has often been called for (Skelton, 2009). In Finland, the teaching profession is more popular among females than males at primary and secondary levels, a trend common in Western cultures (OECD Education at Glance, 2019). To ensure equal opportunities for all, it is critical that the admission procedures as such do not favour either gender. Although some 
Multiple Mini Interview in initial teacher education admissions 7

research has found MMI scores to be unrelated to gender (Humphrey et al., 2008; Reiter et al., 2012), other research has reported that female applicants for medical school tend to receive higher MMI ratings than male applicants (Barbour \& Sandy, 2014; Ross et al., 2017). In addition, research on the impact of age on the MMI performance has documented that older applicants outperform younger applicants (Reiter et al., 2012). Overall, however, research is scant on biases favouring certain subgroups (e.g., age, gender). Therefore, the second goal of the present study was to examine the possible impact of applicant gender and age on MMI performance.

\section{Applicant and Interviewer Reactions}

It is important that both applicants and interviewers have confidence in the admission procedures and perceive them as fair and valid (McCarthy et al., 2017). Prior research in medical education selections shows that applicants and interviewers generally perceive the MMI positively (Dore et al., 2010; Eva et al., 2004a; Patterson et al., 2016; Razack et al., 2009) because of its format of individual interviews and multiple opportunities for the assessment of applicant attributes (Kumar et al., 2009). Although the short duration of interview stations and limited opportunities for applicants to freely discuss their commitment and values have been considered limitations of the MMI (Kumar et al., 2009), applicants have still felt that they could demonstrate their communication skills, critical thinking skills and opinions during the interviews (Cox et al., 2015). Interviewers have considered the multistation format better than the traditional panel interview format (Humphrey et al., 2008; Razack et al., 2009), and they have appreciated the MMI decision-making process because it is free from possible influence of interviewers on each other, which is typical of panel interviews. In addition, because each applicant is being assessed by several different interviewers, the pressure of assessment is lower and encourages interviewers to use the full scale (Kumar et al., 2009). It is possible that the usability of MMI is perceived differently in 
different disciplines, and, thus, the third goal of the present study was to investigate both applicant and interviewer perceptions of MMI in teacher education admissions.

\section{The Present Study}

The present study addressed the following research questions:

RQ1: What is the reliability of the MMI format in ITE admissions?

- How much of the variation in MMI scores in each station is explained by the clustering of applicants to different interviewers and circuits?

- How much of the variation in MMI total scores is 'unwanted' variance, that is, variance attributable to the interviewer, circuit and station?

RQ2: Are there differences in the MMI scores of female and male applicants and between younger and older applicants?

RQ3: What are the applicant and interviewer perceptions of MMI with respect to its validity and usability?

\section{Method}

\section{Participants and Procedure}

The study focused on the locally contextualised MMI used in one Finnish teacher education unit to select students for classroom teacher (grades 1-6) and special education teacher programs. Both ITE programs offer a three-year bachelor's and a two-year master's degree. The selection procedure included two phases; the first phase (cognitive screening) consisted of a source-based exam (four scholarly articles in the field of education, about 140 pages) with multiple-choice questions tapping conceptual comprehension, ability to recall and connect information correctly and reasoning. The scores earned in this exam were used to select the top applicants for the second phase consisting of an aptitude test that included an MMI. In the present study, we focused solely on the reliability and usability of MMI as part of the selection process. 
Multiple Mini Interview in initial teacher education admissions 9

\section{Participants}

The participants of the present study included applicants seeking admission to classroom teacher and/or special education teacher programs and interviewers who assessed them using the MMI format. Based on the scores earned in the first phase exam, 482 applicants participated in the second phase. Of these applicants, 418 agreed to participate in this study, and 304 of them completed a web survey assessing applicant perception of the MMI. The applicants were informed about the purposes of the study, and it was emphasised that taking part in the study was voluntary and would not have any influence on admission decisions. All participants gave their written consent to participate. Participants' mean age was 25.2 (Mdn= $21.9, S D=7.9)$ years, and the majority of the applicants were women $(84 \%)$.

The MMIs were conducted by the staff of the classroom teacher education and special education units and by in-service teachers of the university teacher training school $(n=53)$. Each interviewer assessed from 15 to 88 applicants. Of the interviewers, 28 (53\%) participated in a web survey on their perceptions of the MMI. Of the respondents $75 \%(n=$ $21)$ were women and $25 \%(n=8)$ were men, and their mean age was 48.9 years $(S D=10.8)$. The interviewers responding to the survey gave their written consent for participation.

\section{Procedure}

Multiple Mini Interview. The MMI circuit had five stations, each lasting five minutes, with a three-minute turnaround between stations. The five-minute duration has been found to be a cost-effective solution with only a minimal reducing effect on reliability compared to a longer duration (e.g., an eight-minute duration per station) (Dodson et al., 2009). Further, MMI has been found to generate reliable interview results using only five stations (Fraga et al., 2013). Each applicant rotated through the five-station circuit, meeting a different single interviewer at each station. Five simultaneous five-station circuits operated over four consecutive days, totalling 20 circuits. All interviewers received a four-hour MMI 
training consisting of description of the general aims and implementation of MMI and extensive training on the administration and scoring of the respective station (i.e., one of the five stations).

The MMI stations and criterion-referenced scoring schemes were highly structured in terms of interview questions and the evaluation of responses to ensure that the MMI was administered consistently to all applicants. The same questions were asked from each applicant at the respective stations, and the rating scales for scoring applicants' responses were anchored with descriptions and examples of scores. At each station, an applicant's performance was assessed by a rating scale from 0 to 12 , which was based on the total of scores assigned for station-specific subscales (e.g., total score calculated by adding up the scores from three subscales each with a four-point maximum). An applicant's MMI total score was calculated as a mean of MMI station scores.

An admission committee consisting of ten senior staff members designed the MMI stations. The selection of contents of the MMI stations was based on prior work resulting in a national research-based model of teacher competences (Metsäpelto et al., 2020). The Multidimensional Adapted Process Model of teaching (MAP) was developed through national cooperation between seven Finnish universities with teacher education units, and it represents a shared vision of this comprehensive work. The key competences applicants should have already mastered at entry stage to ITE informed the development of the present MMI stations. After a further literature review on conceptualisation of the selected key competences, five MMI stations were constructed, each station designed to assess a particular non-cognitive competence. The main goals and station formats are summarised in Table 1.

$* * * * * * * * * * * * * * * * * * * * * * *$

Insert Table 1 about here

$* * * * * * * * * * * * * * * * * * * * * * *$ 
Applicant and Interviewer Reactions. Upon completion of the MMI and before leaving the test site, applicants were invited to complete a web survey regarding their perceptions of the MMI. The web survey was administered separately from the selection procedure and applicants were informed that responses to the survey would not have any bearing on selection itself. Interviewers were approached by e-mail approximately six weeks after the MMIs to ask for their participation in a web survey on their perceptions of the MMI and evaluation of its usability.

Perceptions of the MMI were collected from the applicants and interviewers using an identical nine-item questionnaire (Chan et al., 1998). The participants were asked to evaluate the nine statements using a 5-point Likert scale ( 1 = strongly disagree; $5=$ strongly agree). The questionnaire included three subscales, each with three items: 1) fairness (e.g., I feel that using the MMI to select applicants for the teacher education programs is fair); 2) perceived predictive validity (e.g., The results from the MMI can predict how well an applicant will perform on the teacher's work); 3 ) and face validity (e.g., The actual content of the MMI is related to the teacher's work). Cronbach's alphas for the scales were calculated as an indicator of scale reliability. The alphas for applicants' and interviewers' ratings were as follows (interviewer alphas in parenthesis): fairness $=.55(.66)$, predictive validity $=.63(.73)$, face validity $=.65(.87)$.

The web survey for interviewers also included an additional ten items about the feasibility of the MMI (e.g., The MMI was easier to carry out than the previously used [semistructured panel] interview method). The interviewers evaluated the items using a 5-point Likert-scale $(1=$ strongly disagree; $5=$ strongly agree $)$. In the analyses, these were used as single items to describe the interviewers' perceptions regarding the usability and applicability of the MMI in ITE selections.

\section{Analysis Strategy}


We first present descriptive statistics to provide an overview of applicant scores in the five MMI stations and the MMI total score, and the Pearson correlations between them. The five MMI station scores were normally distributed (skewness values ranging from -.82 to .23 and kurtosis values from -.84 to .60), allowing the use of parametric statistical analyses.

Second, intra-class correlations (ICCs) were calculated to investigate how much of the variation in applicant scores was explained by the clustering of applicants to different interviewers (i.e., interviewer effect) and to the five-station circuits (i.e., circuit effect) (RQ1). The ICC is a measure of relatedness of observations within a cluster, and it ranges between 0 and 1 (Killip et al., 2004). An ICC of 0 indicates that there is no correlation of observations within a cluster; and when an ICC is 1 , all observations within a cluster are identical. In the present study, as an index of reliability, we examined whether the MMI scores within an individual interviewer would be more similar than scores derived from different interviewers.

Third, to analyse in more detail the complex structure of variation in the MMI total scores, we used cross-classified multilevel model with three factors to calculate the variance components for the circuit, station and interviewer of the MMI (RQ1). Cross-classification is applied in situations where the data hierarchy is ambiguous (Rashbash \& Browne, 2008; Hox, 2010). For example, students are members of schools and neighbourhoods, but not all students from the same neighbourhood go to same schools and hence neighbourhoods and schools are crossed, while students are nested within them (Rashbash \& Browne, 2008; Hox, 2010). In the case when the contributing factors for the total variation of assessment are crossed, a cross-classified multilevel modelling allows building a statistical model that takes into account the effects of separate variance components on the outcome variable (e.g., Marsh et al., 2008). In the present study, the outcome was the total score earned in the MMI. Applicants moved through five identical stations; hence, the stations were not crossed and 
they were treated as a fixed effect in the cross-classified model. The effects of the stations' relative difficulty level were calculated by using dummy-variables (e.g., station $1 ; 0=$ no, $1=$ yes), and they were regressed on the MMI total score. Applicants were, however, crossed with interviewers as five interviewers out of the total pool of 53 assessed each applicant. In addition, applicants were crossed with circuits because they attended one of the twenty circuits. The goal of the MMI is to detect valid systematic differences between applicants (i.e., intended variance) (Knorr \& Hissbach, 2014). Thus, in our analyses we aimed at exploring the extent of 'unwanted' variance that was attributable to interviewer, station, or circuit. The calculation of ICCs and the cross-classified multilevel models was accomplished using Mplus 7.4 (Muthen \& Muthen, 2015). The confidence intervals for the ICCs were calculated by simulation where sampling variances (between and within level) were used.

Fourth, independent sample t-test was used to compare the scores earned in the five MMI stations and the MMI total score between female and male applicants. Pearson correlation coefficients were calculated between applicant age and the MMI station scores and total scores (RQ2). Finally, minimum and maximum scores, mean scores, and standard deviations were used to portray how the applicants and the interviewers perceived the MMI (RQ3).

\section{Results}

\section{Descriptive Statistics}

Table 2 shows that there was a relatively large variation in mean scores between stations. Applicants received high scores particularly in Station 2 (cultural competence; $M=$ 9.7) while their scores in Station 5 were on average the lowest (collaboration skills; $M=6.8$ ). Correlations between the stations ranged from low to moderate $(\mathrm{R}=.04-.33$; highest correlation being between cultural competence and teacher motivation), indicating that the stations were measuring separate non-cognitive skills. 
$* * * * * * * * * * * * * * * * * * * * * *$

Insert Table 2 about here

$* * * * * * * * * * * * * * * * * * * * * * *$

\section{Interviewer Effects}

Analysis of intraclass correlations provided information on the extent to which variation in applicant scores in each station was explained by the clustering effect of the interviewer and the circuit. The findings presented in Table 3 show that three stations had ICCs less than .10, namely the Stations 1, 2 and 5 assessing applicants' social skills, cultural competence and collaboration skills. Thus, nearly all of the measured variance in these stations was attributable to individual differences between applicants (rather than factors related to interviewer or circuit). In two stations, however, namely Station 4 (emotion management) and Station 3 (motivation for teaching career), ICCs were higher, .18 and .28 respectively, indicating that scores of applicants having the same interviewer resembled each other more strongly in these two stations than in the other stations. The results for analyses with the circuit as a clustering variable show that the five-station circuit to which the applicant had been assigned to had a very small contribution to the variance in the total MMI score.

$* * * * * * * * * * * * * * * * * * * * * * *$

Insert Table 3 about here

\section{Variance Components of the MMI Total Scores}

The findings of the cross-classified multilevel modelling, delineating the variance components of the MMI total score, are shown in Table 4. All variance components were statistically significant. The percentage of variance in the MMI total score explained by interviewer was slightly above $10 \%$, whereas variance explained by the circuit was minimal, 
only $1.4 \%$. This means that there were relatively small differences in MMI total score as a function of either the interviewer or the specific circuit to which the applicant was assigned. The findings are important because they show that MMI scores of applicants could not be attributed to interviewers and circuits but to differences between applicants. The largest 'unwanted' variance component was for the station, meaning that a significant portion of the variance in MMI total scores (19.7\% of total variance) was due to differences between stations. This relatively large station effect indicates that the range of scores given varied between individual stations, thus, varying levels of 'difficulty' were identified between stations. The residual variance component, which includes differences between applicants, as well as a number of other potential sources of variance, was large and statistically significant. Taken together, results of the variance components model analysis suggest that an applicants' MMI total score varied to some degree as a function of the station but notably much less as a function of the circuit the applicants attended to or their interviewers.

$* * * * * * * * * * * * * * * * * * * * * * *$

Insert Table 4 about here

$* * * * * * * * * * * * * * * * * * * * * * *$

\section{Gender and Age Differences}

There were no significant differences in the MMI scores between female and male applicants, as shown in Table 2. Furthermore, the correlations between age and the MMI scores showed no significant associations, except for Station 5 (collaboration skills). Applicants who were older were evaluated as having better collaboration skills, although this association was weak $(r=.10)$.

\section{Interviewer and Applicant Reactions}

Analysis of ratings of both applicants and interviewers indicated that MMI was, on average, perceived to be fair and have high face validity (Table 5). The applicant's responses 
indicated that MMI offered equal opportunities for all applicants to contend for a place in the ITE program and that the contents of the MMI with respect to the skills it assessed were connected to the work of teachers. The ratings concerning perceived predictive validity were somewhat lower, suggesting that applicants were less certain about the MMI's ability to predict an applicant's subsequent ability to work as a teacher. The examination of minimum and maximum scores and standard deviations indicated that the values of scores were spread out over a wide range, indicating relatively large differences within both applicants' and interviewers' perceptions of fairness and the face and predictive validity of MMI.

The interviewers' ratings of MMI as a feasible assessment format for ITE selections were quite positive. Specifically, MMI was considered highly suitable for use as an entrance exam for initial teacher education $(M=4.39)$. Interviewers' ratings indicated that the instructions to implement the MMI (e.g., the structured format of stations with detailed questions, timing and scoring) were clear $(M=4.14)$ and MMI was easier to implement than the previously used semi-structured panel interview format $(M=3.89)$. Interviewers also evaluated the time allotted for each station as sufficiently long in duration $(M=3.79)$. It is noteworthy, however, that on average, the interviewers were less satisfied with the training for administering the MMI stations and the degree of clarity and comprehensibility of contents to the applicants. This finding points to a need to improve these aspects in future ITE selections.

$* * * * * * * * * * * * * * * * * * * * * * * * * * * *$

Insert Table 5 about here

$* * * * * * * * * * * * * * * * * * * * * * * * * * * *$

\section{Discussion}

To our knowledge, this is the first study investigating the use of an MMI in an initial teacher education selection. The analysis of the ICCs showed that the effect of clustering of 
applicants to different interviewers and circuits was mostly small (under 10\%). In two stations, however, the clustering effects were higher (.18 and .28) indicating an elevated interviewer effect. The findings of cross-classified multilevel modelling indicated that the percentages of variance in the MMI total score explained by the interviewer or the circuit were low or minimal, while the variance component for the station was somewhat higher (19.7\% of total variance) indicating varying levels of 'difficulty' between stations. The findings further showed that the associations of MMI scores with the applicant's gender or age were minimal or non-existent. The perceptions of the applicants and interviewers of MMI as indicated by ratings of a web-survey were mostly positive. Taken together, the present study demonstrates that MMI is a feasible selection tool with satisfactory reliability for a high-stakes entrance examination determining who will be the most suitable applicants to enter teacher education programs.

The present analyses show that the clustering of applicants to different interviewers explained only a small amount of variance $(<=8 \%)$ for three out of five MMI stations. This means that scores assigned within the pool of applicants of the same interviewer did not resemble each other more than scores of other applicants by other interviewers, and, thus, it could be determined that the treatment of applicants in the stations was reliable in the majority of the stations. In two stations, intraclass correlations were somewhat higher, suggesting that interviewer bias may partly affect selection scores even in very highly structured tasks with uniform scoring criteria. Clearly, more research is needed to understand the various sources of interviewer bias in MMI stations to improve the reliability of assessment. It should be noted, however, that even when the interviewer effect based on ICCs was found to be slightly higher in two stations - notably the station assessing the applicants' motivation for teaching career - the effect was diluted when the ICC of the five-station 
circuit was taken into account (ICC at .07). This means that the reliability of the overall assessment of applicants across the five stations was within acceptable limits.

Further evidence of the reliability of MMI was obtained from cross-classified multilevel modelling, which shows that the variance component attributable to the interviewer was only slightly more than $10 \%$. In previous studies the amount of variance attributable to the interviewer has ranged from $14 \%$ to $21 \%$ (Eva et al., 2004b; Roberts et al., 2010), often higher than that of the present study. The findings of the cross-classified modelling show that the effect of the station was about a fifth of the overall variance of the MMI total score, suggesting that the level of difficulty of the stations varied significantly (i.e., the applicants on average were assigned lower scores on some stations than some others). This result is not surprising as the stations were designed to function independently, and their level of difficulty was not calibrated relative to one another. The differences in station difficulty, however, do not compromise the reliability of the method because all applicants go through the same stations. The variance component of the station, that is, the difficulty of the task, was twice as large as the variance component of the interviewer, which further supports the conclusion that interviewers generally performed consistently in administering and scoring the MMI. Taken together, the analysis of ICCs and the variance components of the MMI total score indicate an acceptable reliability for the current MMI used in the ITE selections. Thus, it can be concluded that the MMI format is effective in reducing the unreliability that has long been associated with selection interviews into teacher education programs. The research-basis for content of selection, highly structured interview format and a detailed uniform scoring rubric are the likely explanations for these findings. Hence, the use of MMI format in ITE student selections can be seen to successfully respond to the call for more carefully defined and reliable evaluation process. 
The results further show that MMI ratings given to females and males were similar and hence did not favour either gender. This result runs counter to prior findings in other fields, such as those in which female applicants to medical schools have been found to outperform male applicants in MMIs (e.g., Barbour \& Sandy, 2014; Ross et al., 2017). We also found that the age of the applicants was only marginally related to performance in MMI, being related to performance in only one station, namely applicants' collaboration skills. It has been argued that examination of potential biases favouring certain subgroups (e.g., based on gender or age) have often been neglected in student selection studies (Klassen \& Kim, 2018), and the results of this study provide valuable information on this issue with respect to ITE selections. Further studies are needed, however, to examine the possible adverse impact on performance in MMI of applicants belonging, for instance, to different language groups and ethnic minorities.

Successful student selection in any educational institution is greatly strengthened if both the applicants and members of the selecting institute perceive the admissions procedure as fair and well justified. In this study, analyses of ratings of both the applicants and the interviewers indicated that they perceived the MMI to be fair, and it was found to have quite high face validity. These results are in line with earlier findings documenting positive reactions towards MMI in medical education selections (Dore et al., 2010; Eva et al., 2004a; Patterson et al., 2016; Razack et al., 2009). It should be noted, however, that the applicants and interviewers rated the predictive value of the MMI with respect to subsequent success as a teacher less positively. This might be explained by the multidimensional nature of teacher competences, which comprises a large set of skills that may be difficult to define and capture in one admission interview. Admission interviews can by necessity target only a relatively narrow area of the applicants' competences, and hence both the applicants and interviewers may rightfully feel that a broader assessment would be needed to accurately predict future 
success in the teaching profession. In future studies, investigating the true predictive validity of MMI in the field of education using longitudinal follow-up data would be highly valuable.

The web survey results were promising in terms of future development of student selection as the interviewers' ratings clearly indicated that the MMI format was perceived to be easier to implement than the previously used traditional panel interview format. These results corroborate prior findings, which have similarly reported that interviewers consider MMI to be easier to use and superior (Eva et al., 2004b; Humphrey et al., 2008; Razack et al., 2009). There was, however, some variation in the interviewers' ratings regarding the ease of use of MMI, which suggests that some members of the interviewer pool may need more training and clarification of instructions in order to have high confidence. Taking into account both the applicants' and interviewers' positive perceptions towards MMI, it can be concluded that introducing MMI to the ITE selections was seen as a welcome improvement in the validity and reliability of the admission interviews.

\section{Limitations}

One limitation of the present study is that due to the ecological setting, namely conducting the MMI in a high-stakes situation in actual student selections, certain elements regarding the reliability of the MMI could not be investigated. For example, it was not possible to use more than one interviewer per station because the pool of interviewers could not be increased and the budgetary and time resources did not allow an increase in the number of assessment days. In light of prior studies, the use of five stations in the present MMI was the minimum recommended in research on the effect of the number of stations on the reliability of the MMI (Fraga et al., 2013). However, despite these challenges, the effects of both the interviewer and the station were low or moderate for any individual station and their effects were diluted when the effect of circuit in the overall score was taken in to account. 
The second limitation concerns interviewer effects. Since we did not collect information about the interviewers' work experience, education, personality characteristics, attitudes or other individual attributes, it was not possible to examine factors that could explain variability in the MMI ratings between the interviewers. The third caveat concerns the generalisability of the results, which remains limited because only one educational institution participated in this study. While the results need to be replicated in future studies, including several teacher education institutions, they align well with earlier findings that have shown an acceptable reliability of MMI in medical education selections.

\section{Conclusions}

This study reported findings from a successful adoption of MMI into teacher education admission interviews. A highly structured interview format has been suggested to function as a remedy for interviewer bias (Ebmeier $\& \mathrm{Ng}, 2005)$, and the low to moderate interviewer effects noticed in this study corroborated this view. In the present study, the MMI format was well received by both applicants and interviewers, which is a key issue when developing new methods for student selections. In light of this study, the reliability of ITE student selections can be improved by adopting a more rigorous approach to development of selection procedures by responding to the call for research-based admissions (Thomson et al., 2011) and by utilising selection methods that have been proven to work in other fields such as medical education.

\section{References}

Barbour, M. E., \& Sandy, J. R. (2014). Multiple mini interviews for selection of dental students: influence of gender and starting station. Journal of Dental Education, 78(4), 589-596. doi: 10.1002/j.0022-0337.2014.78.4.tb05710.x 
Multiple Mini Interview in initial teacher education admissions 22

Bowles, Hattie Dinham, Scull, \& Clinton (2014). Proposing a comprehensive model for identifying teaching candidates. Australian Educational Researcher, 41, 365-380. doi: $10.1007 / \mathrm{s} 13384-014-0146-\mathrm{Z}$

Chan et al. (1998). Understanding pretest and posttest reactions to cognitive ability and personality tests. Journal of Applied Psychology, 83, 471-485. doi: 10.1037/00219010.83 .3 .471

Cox, W. C., McLaughlin, J. E., Singer, D., Lewis, M., \& Dinkins, M. M. (2015). Development and assessment of the multiple mini-interview in a school of pharmacy admissions model. American Journal of Pharmaceutical Education, 79(4), 53. doi: 10.5688/ajpe79453

Dodson, M., Crotty, B., Prideaux, D., Carne, R., Ward, A., \& De Leeuw, E. (2009). The multiple mini-interview: how long is long enough? Medical Education, 43(2), 168-174. doi: $10.1111 /$ j.1365-2923.2008.03260.x

Dore, K. L., Kreuger, S., Ladhani, M., Rolfson, D., Kurtz, D., Kulasegaram, K., .. \& Reiter, H. I. (2010). The reliability and acceptability of the multiple mini-interview as a selection instrument for postgraduate admissions. Academic Medicine, 85(10), 60-63. doi: 10.1097/ACM.0b013e3181ed442b

Ebmeier, H., \& Ng, J. (2005). Development and field test of an employment selection instrument for teachers in urban school districts. Journal of Personnel Evaluation in Education, 18(3), 201-218. doi: 10.1007/s11092-006-9021-4

Eva, K. W., Reiter, H. I., Rosenfeld, J., \& Norman, G. R. (2004a). The relationship between interviewers' characteristics and ratings assigned during a multiple miniinterview. Academic Medicine, 79(6), 602-609. 
Multiple Mini Interview in initial teacher education admissions 23

Eva, K. W., Rosenfeld, J., Reiter, H. I., \& Norman, G. R. (2004b). An admissions OSCE: The multiple mini-interview. Medical Education, 38(3), 314-326. doi: 10.1046/j.13652923.2004.01776.x

Fraga, J. D., Oluwasanjo, A., Wasser, T., Donato, A., \& Alweis, R. (2013). Reliability and acceptability of a five-station multiple mini-interview model for residency program recruitment. Journal of Community Hospital Internal Medicine Perspectives, 3(3-4), 21362. doi: 10.3402/jchimp.v3i3-4.21362

Griffin, B., Harding, D. W., Wilson, I. G., \& Yeomans, N. D. (2008). Does practice make perfect? The effect of coaching and retesting on selection tests used for admission to an Australian medical school. Medical Journal of Australia, 189(5), 270-273. doi: 10.5694/j.1326-5377.2008.tb02024.x

Hanson, M. D., Kulasegaram, K. M., Woods, N. N., Fechtig, L., Anderson, G. (2012). Modified personal interviews: Resurrecting reliable personal interviews for admissions? Academic Medicine, 87 (10), 1330-1334. doi:

\subsection{7/ACM.0b013e318267630f}

Harasym, P. H., Woloschuk, W., Mandin, H., \& Brundin-Mather, R. (1996). Reliability and validity of interviewers' judgments of medical school candidates. Academic Medicine, $71(1), 40-42$.

Heldenbrand, S. D., Flowers, S. K., Bordelon, B. J., Gubbins, P. O., O’Brien, C., Stowe, C. D., \& Martin, B. C. (2016). Multiple Mini-Interview performance predicts academic difficulty in the PharmD Curriculum. American Journal of Pharmaceutical Education, 80(2), 1-8. doi: 10.5688/ajpe80227

Hox, J. (2010). Multilevel analysis: Techniques and applications. Routledge, New York. 
Humphrey, S., Dowson, S., Wall, D., Diwakar, V., \& Goodyear, H. M. (2008). Multiple mini-interviews: opinions of candidates and interviewers. Medical Education, 42(2), 207-213. doi: 10.1111/j.1365-2923.2007.02972.x

Ingvarson, L. (2013). Recruitment and selection in teacher education. In L. Ingvarson, J. Schwille, M. T. Tatto, G. Rowley, R. Peck, \& S. L. Senk (2013). An analysis of teacher education context, structure, and quality-assurance arrangements in TEDS-M countries: Findings from the iea teacher education and development study in mathematics (TEDS-M) (pp. 165-209). Retrieved from https://files.eric.ed.gov/fulltext/ED545244.pdf\#page=166

Kelly, S., Pogodzinski, B., \& Zhang, Y. (2018). Teaching quality. In B. Schneider (Ed.), Handbook of the Sociology of Education in the 21st Century (pp. 275-296). Springer, Cham.

Killip, S., Mahfoud, Z., \& Pearce, K. (2004). What is an intracluster correlation coefficient? Crucial concepts for primary care researchers. The Annals of Family Medicine, 2(3), 204-208. doi: 10.1370/afm.141

Klassen, R., Durksen, T., Rowett, E., \& Patterson, F. (2014). Applicant reactions to a situational judgment test used for selection into initial teacher training. International Journal of Educational Psychology, 3(2), 104-124. doi: http://dx.doi.org/10.4471/ijep.2014.07

Klassen, R. M., \& Kim, L. E. (2017). Assessing critical attributes of prospective teachers: Implications for selection into initial teacher education programs. Retrieved from: http://eprints.whiterose.ac.uk/124823/

Klassen, R. M., \& Kim, L. E. (2018). Selecting teachers and prospective teachers: A metaanalysis. Educational Research Review, 26, 32-51. doi: 10.1016/j.edurev.2018.12.003 
Klassen, R. M., Kim, L. E., Rushby, J. V., \& Bardach, L. (2020). Can we improve how we screen applicants for initial teacher education? Teaching and Teacher Education, 87. doi: $10.1016 /$ j.tate 2019.102949

Knorr, M., \& Hissbach, J. (2014). Multiple mini-interviews: Same concept, different approaches. Medical Education, 48(12), 1157-1175. doi: 10.1111/medu.12535

Kumar, K., Roberts, C., Rothnie, I., Du Fresne, C., \& Walton, M. (2009). Experiences of the multiple mini-interview: a qualitative analysis. Medical Education, 43(4), 360-367. doi: 10.1111/j.1365-2923.2009.03291.x

McCarthy, J. M., Bauer, T. N., Truxillo, D. M., Anderson, N. R., Costa, A. C., \& Ahmed, S. M. (2017). Applicant perspectives during selection: A review addressing "So what?,"“What's new?," and "Where to next?”. Journal of Management, 43(6), 16931725.

Makransky, G., Havmose, P., Vang, M. L., Andersen, T. E., \& Nielsen, T. (2017). The predictive validity of using admissions testing and multiple mini-interviews in undergraduate university admissions. Higher Education Research \& Development, 36(5), 1003-1016. doi: 10.1080/07294360.2016.1263832

Marsh, H. W., Martin, A. J., \& Cheng, J. H. (2008). A multilevel perspective on gender in classroom motivation and climate: Potential benefits of male teachers for boys? Journal of Educational Psychology, 100(1), 78-95. doi: 10.1037/0022-0663.100.1.78

Metsäpelto, R-L., Poikkeus, A-M., Heikkilä, M., Heikkinen-Jokilahti, K., Husu, J., Laine, A., Lappalainen, K., Lähteenmäki, M., Mikkilä-Erdmann, M., \& Warinowski, A. (2020, February 21). Conceptual framework of teaching quality: A Multidimensional Adapted Process Model of Teaching. Retrieved from psyarxiv.com/52tcv. doi: $10.31234 /$ osf.io/52tcv 
Muthén, L., K. \& Muthén, B., O. (2015). Mplus User's Guide. Seventh Edition. Los Angeles, CA: Muthén \& Muthén

OECD (2019). Education at a Glance 2019: OECD Indicators. OECD Publishing, Paris. doi: $\underline{10.1787 / f 8 d 7880 d-e n}$

Patterson, F., Knight, A., Dowell, J., Nicholson, S., Cousans, F., \& Cleland, J. (2016). How effective are selection methods in medical education? A systematic review. Medical Education, 50(1), 36-60. doi: 10.1111/medu.12817

Pau, A., Jeevaratnam, K., Chen, Y. S., Fall, A. A., Khoo, C., \& Nadarajah, V. D. (2013). The multiple mini-interview (MMI) for student selection in health professions training-a systematic review. Medical teacher, 35(12), 1027-1041. doi: 10.3109/0142159X.2013.829912

Rasbash, J., \& Browne, W. J. (2008). Non-hierarchical multilevel models. In Leeuw J., \& Meijer E. (eds) Handbook of multilevel analysis (pp. 301-334). Springer, New York, NY. doi: 10.1007/978-0-387-73186-5_8

Razack, S., Faremo, S., Drolet, F., Snell, L., Wiseman, J., \& Pickering, J. (2009). Multiple mini-interviews versus traditional interviews: stakeholder acceptability comparison. Medical education, 43(10), 993-1000. doi: 10.1111/j.13652923.2009.03447.x

Reiter, H. I., Lockyer, J., Ziola, B., Courneya, C. A., Eva, K. (2012). Should efforts in favor of medical student diversity be focused during admissions or farther upstream? Academic Medicine, 87(4), 443-448. doi: 10.1097/ACM.0b013e318248f7f3

Reiter, H. I., Eva, K. W., Rosenfeld, J., \& Norman, G. R. (2007). Multiple mini-interviews predict clerkship and licensing examination performance. Medical education, 41(4), 378-384. doi: 10.1111/j.1365-2929.2007.02709.x 
Reiter, H. I., Salvatori, P., Rosenfeld, J., Trinh, K., \& Eva, K. W. (2006). The effect of defined violations of test security on admissions outcomes using multiple miniinterviews. Medical education, 40(1), 36-42. doi: 10.1111/j.1365-2929.2005.02348.x

Roberts, C., Rothnie, I., Zoanetti, N., \& Crossley, J. (2010). Should candidate scores be adjusted for interviewer stringency or leniency in the multiple mini-interview? Medical education, 44(7), 690-698. doi: 10.1111/j.1365-2923.2010.03689.x

Ross, M., Walker, I., Cooke, L., Raman, M., Ravani, P., Coderre, S., \& McLaughlin, K. (2017). Are female applicants rated higher than males on the multiple mini-interview? Findings from the University of Calgary. Academic Medicine, 92(6), 841-846. doi: 10.1097/ACM.0000000000001466

Sabbe, E., \& Aelterman, A. (2007). Gender in teaching: a literature review. Teachers and Teaching: theory and practice, 13(5), 521-538. doi: 10.1080/13540600701561729

Salvatori, P. (2001). Reliability and validity of admissions tools used to select students for the health professions. Advances in Health Sciences Education, 6(2), 159-175. doi:

\subsection{3/A: 1011489618208}

Siu, E., \& Reiter, H. I. (2009). Overview: What's worked and what hasn't as a guide towards predictive admissions tool development. Advances in Health Sciences Education, 14(5), 759-775. doi: 10.1007/s10459-009-9160-8

Skelton, C. (2009). Failing to get men into primary teaching: A feminist critique. Journal of Education Policy, 24(1), 39-54. doi: 10.1080/02680930802412677

Thomson, D., Cummings, E., Ferguson, A. K., Moizumi, E. M., Sher, Y., Wang, X., ... \& Childs, R. A. (2011). A role for research in initial teacher education admissions: A case study from one Canadian university. Canadian Journal of Educational Administration and Policy, 121, 1-23. 
Table 1

MMI stations

\begin{tabular}{|c|c|c|}
\hline Station & Main target of assessment & Format \\
\hline 1 & $\begin{array}{l}\text { Social skills in perspective taking, i.e., } \\
\text { understanding another person's thoughts and } \\
\text { feelings }\end{array}$ & $\begin{array}{l}\text { Scenario and questions requiring } \\
\text { reflection of events }\end{array}$ \\
\hline 2 & $\begin{array}{l}\text { Cultural competence, i.e., skills in relating to } \\
\text { cultural diversity }\end{array}$ & Interview questions \\
\hline 3 & Motivation for pursuit of a teaching career & Interview questions \\
\hline 4 & Skills in managing emotions & $\begin{array}{l}\text { Scenario and questions requiring } \\
\text { reflection of events; self- } \\
\text { reflection }\end{array}$ \\
\hline 5 & $\begin{array}{l}\text { Collaboration skills, i.e., skills for problem } \\
\text { solving in a team work situation }\end{array}$ & $\begin{array}{l}\text { Problem-solving task requiring } \\
\text { collaboration between the } \\
\text { applicant and the interviewer }\end{array}$ \\
\hline
\end{tabular}


Table 2

MMI station score means for total sample and for the female and male applicants, and correlations between study variables.

\begin{tabular}{|c|c|c|c|c|c|c|c|c|c|c|c|c|c|c|c|}
\hline \multirow[b]{2}{*}{ Score/variable ${ }^{\mathrm{a}}$} & \multicolumn{2}{|c|}{ All applicants } & \multicolumn{2}{|c|}{ Female } & \multicolumn{2}{|c|}{ Male } & \multirow[b]{2}{*}{$\mathrm{df}$} & \multirow[b]{2}{*}{$t$} & \multirow[b]{2}{*}{$p$} & \multicolumn{6}{|c|}{ Correlations } \\
\hline & $M$ & $S D$ & $M$ & $S D$ & $M$ & $S D$ & & & & 1 & 2 & 3 & 4 & 5 & 6 \\
\hline 1. Station 1 & 7.5 & 2.1 & 7.6 & 2.1 & 7.1 & 2.1 & 416 & 1.70 & .089 & - & & & & & \\
\hline 2. Station 2 & 9.0 & 2.0 & 9.0 & 2.0 & 8.8 & 2.1 & 416 & 0.94 & .349 & $.18 * *$ & - & & & & \\
\hline 3. Station 3 & 8.3 & 2.0 & 8.3 & 1.9 & 8.3 & 2.2 & 416 & .04 & .969 & .04 & $.33 * *$ & - & & & \\
\hline 4. Station 4 & 9.7 & 1.9 & 9.7 & 1.9 & 9.6 & 2.1 & 416 & 0.32 & .770 & $.19 * *$ & .09 & $.10^{*}$ & - & & \\
\hline 5. Station 5 & 6.8 & 2.1 & 6.7 & 2.0 & 7.3 & 2.5 & 81.93 & -1.85 & .068 & $.15^{* *}$ & $.17^{* *}$ & $.17^{* *}$ & $.12 *$ & - & \\
\hline $\begin{array}{l}\text { 6. MMI Total } \\
\text { score }\end{array}$ & 6.9 & 0.9 & 6.9 & 0.9 & 6.8 & 1.1 & 416 & 0.28 & .783 & $.55 * *$ & $.62 * *$ & $.57 * *$ & $.51 * *$ & $.58 * *$ & - \\
\hline 7. Age & 25.2 & 7.9 & 25.5 & 8.5 & 23.6 & 3.7 & - & - & - & -.01 & -.03 & -.00 & -.01 & $.10^{*}$ & -.01 \\
\hline
\end{tabular}

Note. The scores ranged between $0-12 .{ }^{*}$ indicates $\mathrm{p}<.05 . * *$ indicates $\mathrm{p}<.01 .^{\text {a }} 1$ Social skills, 2 Cultural competence 3 Teacher motivation,

4 Emotion management, 5 Collaboration skills 
Table 3

Intraclass correlations (ICC) of the five MMI stations (in ascending order of the ICC) and the five-station circuits

\begin{tabular}{|c|c|c|c|}
\hline \multirow[b]{2}{*}{ Clustering variable } & \multirow[b]{2}{*}{ ICC } & \multicolumn{2}{|c|}{$95 \%$ Confidence interval } \\
\hline & & Lower bound & Upper bound \\
\hline \multicolumn{4}{|l|}{ Interviewer $^{\mathrm{a}}$} \\
\hline Station 1 & $.05 * *$ & .00 & .11 \\
\hline Station 5 & $.06^{*}$ & .00 & .12 \\
\hline Station 2 & $.08^{*}$ & .00 & .16 \\
\hline Station 4 & $.18^{* *}$ & .03 & .32 \\
\hline Station 3 & $.28 * *$ & .11 & .46 \\
\hline \multicolumn{4}{|l|}{ 5-station circuit } \\
\hline Total MMI-score & $.07 *$ & .00 & .14 \\
\hline
\end{tabular}


Multiple Mini Interview in initial teacher education admissions 2

Table 4

Variance components for Multiple Mini Interview total scores

\begin{tabular}{lll}
\hline Source of variance & Variance component & Percentage of total variance \\
\hline Interviewer & 0.60 & 11.6 \\
Circuit & 0.07 & 1.4 \\
Station & 1.02 & 19.7 \\
Residual & 3.49 & 67.4 \\
Total & 5.18 & 100 \\
\hline
\end{tabular}


Table 5

Applicants' and Interviewers' Responses to Statements on MMIs Scored on a 5-point Likert Scale (1-5)

\begin{tabular}{|c|c|c|c|c|}
\hline Item/Scale & $\begin{array}{l}\text { Minimum } \\
\text { score }\end{array}$ & $\begin{array}{l}\text { Maximum } \\
\text { score }\end{array}$ & $\begin{array}{l}\text { Mean } \\
\text { score }\end{array}$ & $S D$ \\
\hline \multicolumn{5}{|l|}{ Applicants } \\
\hline Face validity & 2.33 & 5.00 & 4.01 & 0.58 \\
\hline Fairness & 2.00 & 5.00 & 3.92 & 0.57 \\
\hline Predictive validity & 1.00 & 4.67 & 2.66 & 0.61 \\
\hline \multicolumn{5}{|l|}{ Interviewers } \\
\hline Face validity & 2.00 & 5.00 & 3.89 & 0.79 \\
\hline Fairness & 2.33 & 4.67 & 3.77 & 0.70 \\
\hline Predictive validity & 1.67 & 4.33 & 2.90 & 0.61 \\
\hline The MMI is a suitable method of selection as part of the ITE selection process. & 3.00 & 5.00 & 4.39 & 0.74 \\
\hline The length of the MMI stations (five minutes) was long enough. & 2.00 & 5.00 & 4.18 & 0.86 \\
\hline The instructions I received to implement the MMI were clear and understandable. & 2.00 & 5.00 & 4.14 & 0.71 \\
\hline The level of difficulty in MMI stations was appropriate for those applying for ITE. & 2.00 & 5.00 & 3.96 & 0.79 \\
\hline $\begin{array}{l}\text { For me, it was easier to conduct the MMI than the interview format we had } \\
\text { previously. }\end{array}$ & 1.00 & 5.00 & 3.86 & 1.15 \\
\hline The competence or skill I was assessing was relevant and easy to understand. & 2.00 & 5.00 & 3.79 & 0.83 \\
\hline
\end{tabular}


Multiple Mini Interview in initial teacher education admissions 2

\begin{tabular}{|c|c|c|c|c|}
\hline The amount of time allotted for rating each applicant (three minutes) was sufficient. & 1.00 & 5.00 & 3.79 & 1.32 \\
\hline The training for the MMI interviewers was adequate. & 1.00 & 5.00 & 3.61 & 1.07 \\
\hline The contents of the MMI stations were clear and easy for applicants to understand. & 2.00 & 5.00 & 3.57 & 1.03 \\
\hline The workload involved in preparing for the MMI was excessive. & 1.00 & 5.00 & 2.32 & 0.77 \\
\hline
\end{tabular}

